\title{
There has never been a more important time to think about our future healthcare
}

\section{DOI: 10.7861/fhj.ed-7-2-1}

Welcome to this edition of the Future Healthcare Journal (FHJ), the first to contain some online-only content due to continued growth of the journal.

May I first pay tribute to the authors, editors, editorial team and publications team who have made it possible to produce this edition in extraordinary times.

We all feel that the $\mathrm{FH}$ J is of particular relevance and importance at this moment.

We have unashamedly returned to the theme of education and learning for this issue. It is at the core of preparing our healthcare staff to cope with changing circumstances and new challenges, immediate and in the future. Dr Emma Vaux and Dr Jo Szram have commissioned and collated a series of excellent articles, and their own editorial highlights these and puts them into context.

In addition, we have a number of diverse papers, short reports and letters covering quality improvement together with cogent opinion pieces. Not only do we have the articles in this, the print edition, but our website has additional papers which I commend to you (www.rcpjournals.org/content/futurehosp). In partnership with Clinical Medicine we have collated a number of articles linked to COVID-19, and pandemic management in general (www.rcpjournals.org/covid-19).

We have some very timely papers. Among these, Dr Birns et al describe the use of a formally evaluated workshop to support educational supervisors in aiding doctors returning to practice. ${ }^{1}$ Dr Steel and colleagues study undertook a quality improvement project on the subject of advanced care planning. ${ }^{2}$ By the use of 'ward champions', they significantly improved clinical practice over a period of 12 months.

Many trusts, prompted by NHS England, have invested substantial resources in analysis of hospital deaths. Structured mortality reviews are now widely embedded. It is therefore significant that Dr Tiwari et al find that such reviews, plus a broad range of other interventions, do link to reduced hospital mortality. ${ }^{3}$ Other subjects covered in this issue include personal health records, discharge summaries and communities of practice.

Recent on-line first publications include a paper from Dr Adelaja et al describing a preparedness tool for COVID-19 but relevant to other outbreaks. ${ }^{4}$ In addition, Dr Aujayeb and team report how, in response to the reorganisation of their hospital for the pandemic, they consolidated services for malignant pleural and peritoneal effusions. ${ }^{5}$ The transformed service has advantages that are likely to make at least some aspects of the redesign permanent.

July is 'Sustainability Month'. The Royal College of Physicians and its family of journals are committed to embracing this month of events as part of a long-term goal to work responsibly and sustainably. We already offer an opt-out for the print version for those who prefer reading our journal online or perhaps currently have more than one person in the household receiving a print copy; to apply, log into 'My RCP' (www.rcplondon.ac.uk/user) and click on 'Update your contact details' where you will find an option to opt out of receiving printed publications. This is our last plastic wrapped edition as we are changing to a compostable packaging. There is an additional cost, but we believe this is outweighed by the greater good. We are also progressing our website; articles can appear on-line ahead of print and the website is increasingly the primary source of content for our readership.

I must of course now return explicitly to the COVID-19 pandemic. On behalf of the FHJ team and myself, we send our thanks to all our readership and healthcare workers for your endeavour, commitment and care.

It was apparent from early on that health services would be changed forever by the pandemic. The FHJ has been promoting a debate about the legacy of this crisis through our website (www.rcpjournals.org), through social media (@FutureHealth]) and, in due course, in print. Please participate in this debate and engage your friends and colleagues.

My early reflections are of exhaustion and sadness, but also of transformation at a speed previously unimaginable in the health sector. We are interacting with each other and with our patients in new, often more efficient and effective, ways. A 'can do' culture now pervades our management and a generation of leaders have appeared, drawing on the diversity of our workforce. We are learning what is truly necessary in providing healthcare and, equally, how much of what we have been doing is not. The landscape of our patients and their resource-needs has changed. I believe that once the current crisis is over, the NHS going forward can be leaner, more resource efficient and more appropriate for our population. Only if we commit to achieving this, will we have provided a meaningful legacy for all those whose lives were lost or transformed by the COVID-19 pandemic.

\section{Dr Kevin Fox} Editor-in-chief

\section{References}

1 Birns J, Mullender C, Balch I, Bryant C, Deaner A. Evaluation of training programmes mapped to the new internal medicine curriculum. FHJ 2020;7:116-9.

2 Steel A, Bertfield D. Increasing advance care planning in the secondary care setting: A quality improvement project. FHJ 2020;7:137-42.

3 Tiwari D, O'Donnell A, Renaut R, Richardson T, Allen S. Reducing hospital mortality: Incremental change informed by structured mortality review is effective. FHJ 2020;7:143-8.

4 Adelaja I, Sayma M, Walton $\mathrm{H}$ et al. A comprehensive hospital agile preparedness (CHAPs) tool for pandemic preparedness, based on the COVID-19 experience. FHJ 2020;7:165-8.

5 Aujayeb A. Consolidating malignant pleural and peritoneal services in the COVID-19 era. FH] 2020;7:161-2.

$\begin{array}{ll}\text { Members of the editorial board } & \\ \text { Suzie Bailey } & \text { Graham Foulkes } \\ \text { Rodger Charlton } & \text { Kevin Fox } \\ \text { Mohsin Choudry } & \text { Neil Howie } \\ \text { John Dean } & \text { Linda Milnes } \\ \text { Julia Ellis } & \text { Anenta Ramakrishnan }\end{array}$

Joanna Szram

Mark Temple

Louella Vaughan

Emma Vaux

Sheena Visram 